\title{
Direct ester condensation catalyzed by bulky diarylammonium pentafluorobenzenesulfonates
}

\author{
Akira Sakakura, Shoko Nakagawa \& Kazuaki Ishihara \\ Graduate School of Engineering, Nagoya University, Chikusa, Nagoya 464-8603, Japan. Correspondence should be addressed to K.I. (ishihara@cc.nagoya-u.ac.jp). \\ Published online 5 July 2007; doi:10.1038/nprot.2007.254

\begin{abstract}
A protocol for ester condensation between equimolar amounts of carboxylic acids and alcohols catalyzed by bulky diarylammonium pentafluorobenzenesulfonate is described. We also present procedures for the synthesis of $N$-(2,6-diisopropylphenyl)- $N$ mesitylammonium pentafluorobenzenesulfonate. The present ester condensation proceeds well under mild conditions even without the removal of generated water. The synthesis of $\mathrm{N}$-(2,6-diisopropylphenyl)- $\mathrm{N}$-mesitylammonium pentafluorobenzenesulfonate will take $\sim 5$ days. The ester condensation reactions will take $\sim 6 \mathrm{~h}$ to 3 days.
\end{abstract}

\section{INTRODUCTION}

The ester condensation reaction is among the most fundamental organic transformations, and more environmentally benign alternative synthetic approaches to the ones currently used are in strong demand by the chemical industry ${ }^{1}$. Conventionally, the ester condensation reaction of carboxylic acids with alcohols is catalyzed by Brønsted acids such as $\mathrm{HCl}, \mathrm{H}_{2} \mathrm{SO}_{4}$, $p$-toluenesulfonic acid and so on for acid-resistance substrates. For acid-sensitive substrates, weak Brønsted acids such as pyridinium p-toluenesulfonate should be used. However, these have lower catalytic activities and the reactants that can be used are rather limited. With regard to green chemistry, in particular with respect to atom economy and E-factor, several catalytic methods for the ester condensation reaction between equimolar amounts of carboxylic acids and alcohols have been developed ${ }^{2-6}$. Conventionally, in fact, esterifications are conducted with an excess of carboxylic acids or alcohols against its reaction counterpart in the presence of an acid catalyst, or with a stoichiometric dehydrating reagent or activated carboxylic acid derivative in the presence of a stoichiometric amount of base. The use of excess amounts of substrates is a wasteful practice in itself. Furthermore, the use of stoichiometric dehydrating reagents or activated carboxylic acid derivatives leads to the formation of significant amounts of undesired by-products. Purifying the crude products from (excess) substrates or from reaction by-products is a rather demanding task-also in financial termsrequiring additional apparati and additional amounts of materials, energy (e.g., for azeotropic reflux) and time. It is therefore evident why the direct catalytic condensation between equimolar amounts of carboxylic acids and alcohols that does not require the presence of dehydrating agents is, at least in principle, such an attractive synthetic goal. Among these 'green' catalytic condensations, metalfree organocatalytic methods are particularly desirable, especially for industrial processes. In 2000, Tanabe and co-workers ${ }^{2}$ reported that diphenylammonium triflate $\left(\left[\mathrm{Ph}_{2} \mathrm{NH}_{2}\right]^{+}[\mathrm{OTf}]^{-}, \quad 1.0-10\right.$ $\mathrm{mol} \%$ ) efficiently catalyzed the ester condensation reaction at 80 ${ }^{\circ} \mathrm{C}$ without the need for removal of water. Unfortunately, however, as $\left[\mathrm{Ph}_{2} \mathrm{NH}_{2}\right]^{+}[\mathrm{OTf}]^{-}$is the salt of a superacid (trifluoromethansulfonic acid $(\mathrm{TfOH}))$ and a weak base $\left(\mathrm{Ph}_{2} \mathrm{NH}\right)$, it is a strong Brønsted acid, and as such is difficult to use in the reaction of sterically demanding and acid-sensitive alcohols.

In the course of our continuing study on environmentally benign dehydration catalysts, we have developed N,N-dimesitylammo- nium pentafluorobenzenesulfonate (3) and $N$-(2,6-diisopropylphenyl)- $N$-mesitylammonium pentafluorobenzenesulfonate (4) as mild and selective ester condensation catalysts ${ }^{7-9}$. A scheme for the synthesis of ammonium catalysts 3 and 4 is shown in Figure 1. N,N-Dimesitylamine (1) is prepared from 2,4,6-trimethylaniline by palladium-catalyzed cross-coupling with 2,4,6-mesitylbromide $^{10,11}$. The reaction of $\mathbf{1}$ with an equimolar amount of pentafluorobenzenesulfonic acid $\left(\mathrm{C}_{6} \mathrm{~F}_{5} \mathrm{SO}_{3} \mathrm{H}\right)$, which is prepared from pentafluorobenzenesulfonyl chloride by hydrolysis, gives ammonium salt $\mathbf{3}$. This catalyst $\mathbf{3}$ has been commercially available from Tokyo Chemical Industry Co., Ltd (TCI) since January 2007. Catalyst 4 can be prepared from 2,6-diisopropylaniline by an analogous procedure. It is, in particular, the synthesis of catalyst 4 that is detailed in the PROCEDURE section.

$\mathrm{C}_{6} \mathrm{~F}_{5} \mathrm{SO}_{3} \mathrm{H}\left(\mathrm{p} K_{\mathrm{a}}\left(\mathrm{CD}_{3} \mathrm{CO}_{2} \mathrm{D}\right)=11.1, H_{0}=-3.98\right)$ is a weaker acid than $\mathrm{TfOH}\left(\mathrm{p} K_{\mathrm{a}}\left(\mathrm{CD}_{3} \mathrm{CO}_{2} \mathrm{D}\right)=-0.74, H_{0}=-14.00\right)$, concentrated $\mathrm{H}_{2} \mathrm{SO}_{4}\left(\mathrm{pK}_{\mathrm{a}}\left(\mathrm{CD}_{3} \mathrm{CO}_{2} \mathrm{D}\right)=7.5, \mathrm{H}_{0}=-11.93\right)$ and $p$-toluenesulfonic acid $\left(\mathrm{p} K_{\mathrm{a}}\left(\mathrm{CD}_{3} \mathrm{CO}_{2} \mathrm{D}\right)=8.5, H_{0}=-4.5\right)$. This means that 3 and 4 are milder acids than the corresponding ammonium triflates, sulfates and tosylates. Nevertheless, $\mathbf{3}$ and $\mathbf{4}$ have much higher catalytic activities than Tanabe catalyst $\left(\left[\mathrm{Ph}_{2} \mathrm{NH}_{2}\right]^{+}[\mathrm{OTf}]^{-}\right.$) (see data in Fig. 2), owing to the hydrophobic environment created around the ammonium protons in the catalyst ${ }^{12}$. Even though the ester

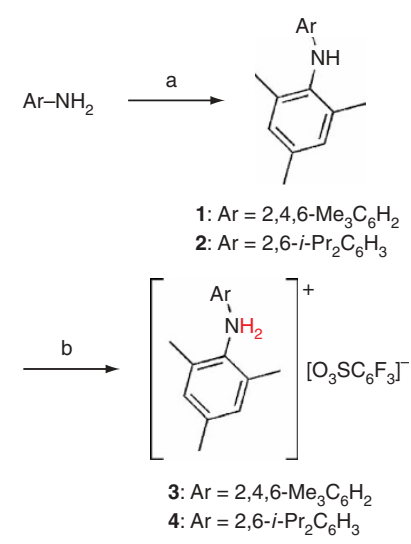

Figure 1 | Scheme for the synthesis of ammonium catalysts 3 and $\mathbf{4}$. (a) 2,4,6-mesitylbromide, $\mathrm{Pd}(\mathrm{dba})_{2}$, BINAP, $t$-Bu ONa, toluene, reflux, (b) $\mathrm{C}_{6} \mathrm{~F}_{5} \mathrm{SO}_{3} \mathrm{H}$, toluene. 
condensation was performed under heating without the removal of water, the reaction proceeded well without any deceleration owing to the generated water.

The $\mathrm{X}$-ray single-crystal structures of $\mathbf{3}$ and $\left[\mathrm{Ph}_{2} \mathrm{NH}_{2}\right]^{+}[\mathrm{OTf}]^{-}$are shown in Figure 3. The crystals obtained were dimeric cyclic ion pairs composed of two diarylammonium cations and two arenesulfonate anions. Interestingly, the dimeric cyclic ion pair of $\mathbf{3}$ was stabilized by two intermolecular $\pi-\pi$ interactions as well as four hydrogen bondings, whereas there was no intermolecular $\pi-\pi$ interaction in the ion pair of $\left[\mathrm{Ph}_{2} \mathrm{NH}_{2}\right]^{+}$ $[\mathrm{OTf}]^{-}$. It is conceivable that a hydrophobic wall' prevents polar water molecules from gaining access to the active site of the catalysts and thus inhibits the inactivation of the catalyst by water (Fig. 3). Furthermore, the steric bulkiness of the mesityl and pentafluorophenyl groups in the catalyst suppressed the dehydrative elimination of secondary alcohols to produce alkenes.

When the ester condensation of 4-phenylbutyric acid with cyclododecanol (5; see Fig. 2) was conducted in the presence of Tanabe catalyst ( $5 \mathrm{~mol} \%)$ in heptane under reflux conditions (bath temperature $115{ }^{\circ} \mathrm{C}$ ), a significant amount of the undesired cyclododecene (7) was produced along with cyclododecyl 4-phenylbutyrate (6) (Fig. 2, graph a). The use of dimesitylammonium triflate $\left(\left[\mathrm{Mes}_{2} \mathrm{NH}_{2}\right]^{+}[\mathrm{OTf}]^{-}\right)$showed higher catalytic activity than $\left[\mathrm{Ph}_{2} \mathrm{NH}_{2}\right]^{+}[\mathrm{OTf}]^{-}$and reduced the production of 7 (Fig. 2, graph a). Furthermore, the ester condensation catalyzed by 3 ( $5 \mathrm{~mol} \%)$ proceeded more rapidly, and the production of 7 decreased (Fig. 2, graph a). The use of less-polar solvents such as heptane is important. The catalytic activities of $\mathbf{3}$ and $\mathbf{4}$ increased in such lesspolar solvents, to produce esters in high yields. One of the
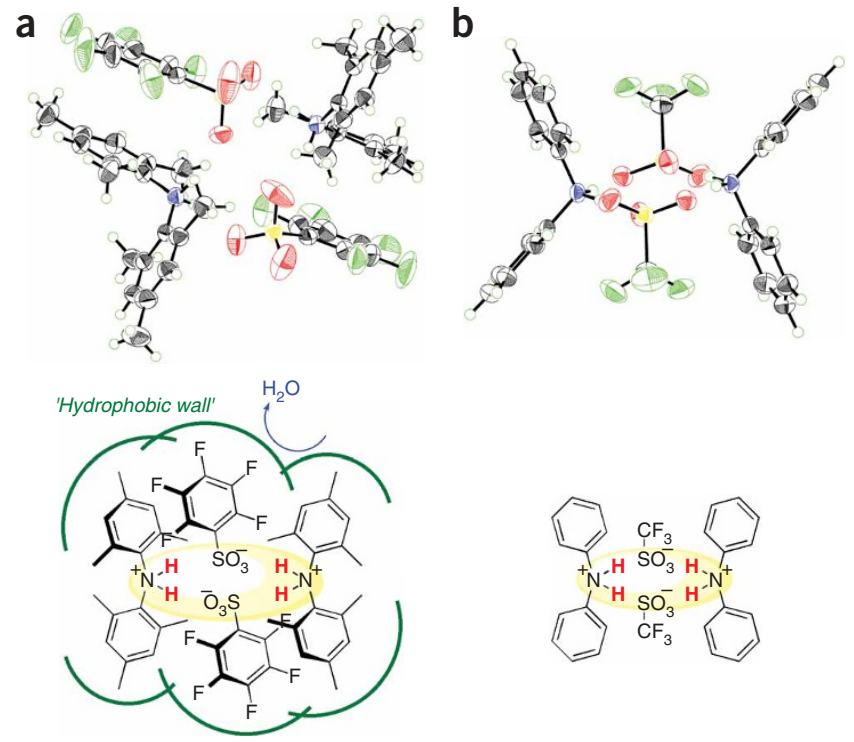

Figure 3 | Structures of the catalysts. Top: ORTEP diagrams of $\mathrm{X}$-ray singlecrystal structure of 3 (a) and $\left[\mathrm{Ph}_{2} \mathrm{NH}_{2}\right]^{+}[\mathrm{OTf}]^{-}(\mathbf{b}) . \mathrm{F}=$ green, $\mathrm{N}=$ blue, $0=$ red, $\mathrm{S}=$ yellow. Bottom: Schematic representation of the active sites (yellow) and 'hydrophobic wall' (green). limitations of the present method is the need for less-polar solvents: it is difficult to perform ester condensation of hydrophilic substrates that cannot dissolve in less-polar solvents.

Typically, the ester condensations of 1:1 mixtures of carboxylic acids and alcohols are carried out in the presence of 3 or 4 (1-5 mol\%) in heptane by heating at $80{ }^{\circ} \mathrm{C}$ without the removal of water. Sterically demanding alcohols are condensed to produce the corresponding esters in high yields. For example, when the ester condensation of 4-phenylbutyric acid with 6-undecanol (1.0 equiv.) was performed in the presence of $4(5 \mathrm{~mol} \%)$ in heptane under heating conditions without the removal of water, the corresponding ester was obtained in $88 \%$ yield along with 5 -undecene $(3 \%)$ (Fig. 4). In Box 1, a detailed protocol for this reaction is reported. Esterification with 1,2-diols proceeded well to give the corresponding diesters in high yields, while Lewis acidic metal salts were not suitable for use with these diols owing to tight chelation with metal ions ${ }^{13}$. For example, the condensation between cis-1,2-cyclohexanediol and 4-phenylbutyric acid with $\mathbf{4}$ gave the corresponding diester in $90 \%$ yield, while no esterification product was obtained by heating a mixture of 1,2-butanediol and 1-adamantanecarboxylic acid in toluene in the presence of $\mathrm{HfCl}_{4} \cdot(\mathrm{THF})_{2}$. In addition, we have been able to recover and reuse the bulky diarylammonium pentafluorobenzenesulfonate catalyst immobilized on a polystyrene support without any loss of catalytic activity more than 10 times $^{7,8}$. On the contrary, a polystyrene-supported diarylammonium triflate could not be prepared, as the polymer support decomposed with superacidic $\mathrm{TfOH}$.

Ester condensation reactions with more reactive primary alcohols proceeded even at ambient temperature $\left(22{ }^{\circ} \mathrm{C}\right)$ without solvents. Several carboxylic acids were esterified with 1.1 equiv. of methanol in good yield in the presence of $\mathbf{3}(1 \mathrm{~mol} \%)$. For example, when condensation between 4-phenylbutyric acid and methanol (1.1 equiv.) was carried out in the presence of $3(1 \mathrm{~mol} \%)$ without the removal of water for $24 \mathrm{~h}$, the corresponding ester was obtained in $95 \%$ yield (Fig. 5). This reaction can be carried out by the same protocol as that of the reaction in Figure 4 but without the use of solvent (heptane) and heating. 1-Octanol was also reactive, albeit slightly less reactive than methanol ${ }^{8}$. Octyl methoxyacetate was obtained in $74 \%$ yield under the same conditions described in Figure 5. 


\section{MATERIALS}

REAGENTS

$\cdot \mathrm{N}, \mathrm{N}$-Dimesitylammonium pentafluorobenzenesulfonate (TCI, cat. no. D3293)

- Mesityl bromide (TCI, cat. no. B1261)

-2,6-Diisopropylaniline (TCI, cat. no. D1755)

- Bis(dibenzylidene acetone)palladium $(0)\left(\mathrm{Pd}(\mathrm{dba})_{2}\right.$; Sigma-Aldrich, cat. no. 227994)

- $( \pm)-2,2^{\prime}$-Bis(diphenylphosphino)-1,1'-binaphthalene (( \pm )-BINAP;

Sigma-Aldrich, cat. no. 481084)

-Sodium tert-butoxide (Wako, cat. no. 196-10922)

- Pentafluorobenzenesulfonyl chloride (TCI, cat. no. P0934)

- Toluene (Kanto, dehydrated, cat. no. 40500)

- Distilled water (Wako, cat. no. 042-16973)

- Silica gel (Merck, silica gel 60 (0.040-0.063 mm), 230-400 mesh ASTM, cat. no. 109385)

- Thin-layer silica gel plates (Merck, silica gel $60 \mathrm{GF}_{254}, 0.25 \mathrm{~mm}$, cat. no. 105715)

- Saturated $\mathrm{NaCl}$ aqueous solution

- Anhydrous sodium sulfate

- Diethyl ether

-Hexane

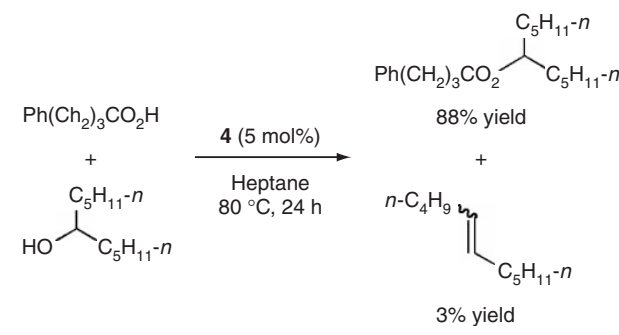

Figure 4 | Ester condensation of 4-phenylbutyric acid with 6-undecanol.

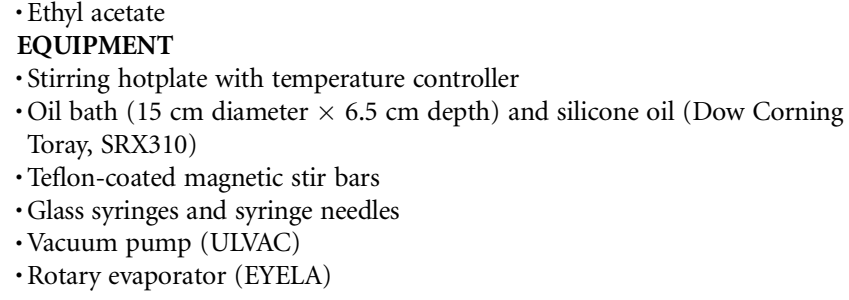

\section{PROCEDURE}

\section{Synthesis of $\mathrm{N}$-(2,6-diisopropylphenyl)-N-(2,4,6-mesityl)amine (2) $\bigcirc$ TIMING $\sim 2-3$ days}

1) Place $9.6 \mathrm{~g} \mathrm{(100} \mathrm{mmol)} \mathrm{sodium} \mathrm{tert-butoxide,} 575 \mathrm{mg}(1.0 \mathrm{mmol}) \mathrm{Pd}(\mathrm{dba})_{2}(10 \mathrm{~mol} \%), 934 \mathrm{mg}(1.5 \mathrm{mmol})( \pm)$-BINAP (15 mol\%) and $50 \mathrm{ml}$ toluene (dehydrated) in a $200 \mathrm{ml}$ round-bottomed flask containing a Teflon-coated magnetic stir bar, and cap the flask with a three-way stopcock with a $24 / 40$ joint.

2| Fit the three-way stopcock with a balloon and a dual bank manifold connected to a vacuum pump and a nitrogen tank. Turn the magnetic stirrer on.

3| Evacuate the flask using a vacuum pump via the three-way stopcock ( $\sim 0.5 \mathrm{~min})$, and fill the flask and the balloon with nitrogen.

4| Successively add $5.0 \mathrm{ml}(33 \mathrm{mmol})$ mesityl bromide and $1.89 \mathrm{ml}(10 \mathrm{mmol})$ 2,6-diisopropylaniline, and recap with the three-way stopcock.

5| Fit a reflux condenser between the flask and the three-way stopcock.

6| Evacuate the flask using a vacuum pump via the three-way stopcock ( $\sim 0.5 \mathrm{~min})$, and fill the flask and the balloon with nitrogen. Repeat this operation three times.

7| Have tap water flow through the reflux condenser.

8| Heat the flask in an oil bath $\left(\sim 120^{\circ} \mathrm{C}\right)$ under reflux conditions.

PAUSE POINT Stir the reaction mixture vigorously at this temperature for 48-60 h.

9| Remove the flask from the oil bath and allow the reaction mixture to cool to ambient temperature.

10| Add $50 \mathrm{ml}$ of water to the flask, and stir the mixture vigorously for $15 \mathrm{~min}$.

11| Transfer the aqueous layer to a separatory funnel and extract it with three $50 \mathrm{ml}$ portions of diethyl ether.

12) Combine the organic layer and the extracts, and wash them with brine (saturated $\mathrm{NaCl}$ aqueous solution, $50 \mathrm{ml}$ ).

13 Dry the solution with the addition of anhydrous sodium sulfate $(\sim 50 \mathrm{~g})$ until sodium sulfate no longer adsorbs water (it will appear powdery instead of gelatinous), and keep it for $\sim 10$ min.

14| Filter the mixture under an aspirator vacuum through a glass filter (G3) to remove sodium sulfate and collect the filtrate in a flask.

15| Evaporate solvents from the filtrate using a rotary evaporator at $\sim 30^{\circ} \mathrm{C}$ under vacuum (10-20 Torr).

16 Pack a chromatography glass column $(4.2 \mathrm{~cm}$ diameter $\times 50 \mathrm{~cm}$ length) with $\sim 400 \mathrm{ml}$ silica gel using hexane.

17| Load a solution of the crude product in $\sim 20 \mathrm{ml}$ hexane on top of the silica gel using a pipette. 


\section{BOX 1 | TYPICAL PROCEDURE FOR ESTER CONDENSATION}

\section{MATERIALS}

REAGENTS

- 4-Phenylbutyric acid (TCI, cat. no. P0643)

- 6-Undecanol (TCI, cat. no. U0040)

- Heptane

- Triethylamine (Wako, cat. no. 209-02656)

- Hexane

- Ethyl acetate

- Thin-layer silica gel plates (Merck, silica gel $60 \mathrm{GF}_{254}, 0.25 \mathrm{~mm}$, cat. no. 105715)

- Silica gel (Merck, silica gel $60(0.040-0.063 \mathrm{~mm}), 230-400$ mesh ASTM, cat. no. 109385)

EQUIPMENT

- Stirring hotplate with temperature controller

- Oil bath (15 cm diameter $\times 6.5 \mathrm{~cm}$ depth) and silicone oil (DOW CORNING TORAY, SRX310)

- Teflon-coated magnetic stir bars

- Glass syringes and syringe needles

- Vacuum pump (ULVAC)

- Rotary evaporator (EYELA)

\section{PROCEDURE}

1. Place $164 \mathrm{mg}(1.0 \mathrm{mmol})$ 4-phenylbutyric acid, $172 \mathrm{mg}(1.0 \mathrm{mmol}) 6$-undecanol and $29.9 \mathrm{mg}(0.050 \mathrm{mmol}) 4$ in a glass test tube $(18 \mathrm{~mm}$ diameter $\times 85 \mathrm{~mm}$ length with a $15 / 25$ joint) containing a Teflon-coated magnetic stir bar.

2. Add $2 \mathrm{ml}$ heptane and cap with a three-way stopcock fitted with a balloon for pressure relief.

3. Heat the flask in an oil bath $\left(80^{\circ} \mathrm{C}\right)$.

PAUSE POINT Stir the mixture at this temperature for $24 \mathrm{~h}$.

$\triangle$ CRITICAL STEP As far as possible, keep the reaction temperature at $80^{\circ} \mathrm{C}$. When ester condensation with secondary or tertiary alcohols is conducted at $100{ }^{\circ} \mathrm{C}$ or higher temperature, the yields of alkenes, which are produced as by-products by the dehydration of alcohols, will increase. The reaction should be traced by a thin-layer chromatography (TLC) analysis.

4. Remove the flask from the oil bath and allow the reaction mixture to cool to ambient temperature.

5. Add $\sim 0.1 \mathrm{ml}$ triethylamine, and transfer the reaction mixture to a round-bottomed flask.

6. Evaporate solvents from the reaction mixture using a rotary evaporator at $\sim 30^{\circ} \mathrm{C}$ under vacuum ( 20 Torr).

7. The conversion yield of the ester can be estimated by ${ }^{1} \mathrm{H}$ NMR analysis of the obtained crude product: $\delta 4.89$ (quint, $J=6.5 \mathrm{~Hz}, 1 \mathrm{H}, 6$-undecyl 4-phenylbutyrate (- $\mathrm{CH}(\mathrm{OCOR})-)), 3.61(\mathrm{~m}, 1 \mathrm{H}, 6$-undecanol $(-\mathrm{CH}(\mathrm{OH})-))$ and 5.29-5.45 (m, 2H, 5-undecene $(-\mathrm{CH}=\mathrm{CH}-))$.

PAUSE POINT The crude product obtained might be stored under nitrogen at ambient temperature for one night. Nevertheless, in our laboratory, we usually store the crude product under nitrogen in a $-20{ }^{\circ} \mathrm{C}$ freezer until purification.

8. Pack a chromatography glass column $(0.7 \mathrm{~cm}$ diameter $\times 36 \mathrm{~cm}$ length $)$ with $\sim 20 \mathrm{ml}$ silica gel using hexane.

9. Load a solution of the crude product in $2 \mathrm{ml} \mathrm{50:1} \mathrm{(vol/vol)} \mathrm{hexane/ethyl} \mathrm{acetate} \mathrm{on} \mathrm{top} \mathrm{of} \mathrm{the} \mathrm{silica} \mathrm{gel} \mathrm{using} \mathrm{a} \mathrm{pipette.}$

10. Elute the column under pressure, initially with $50: 1(\mathrm{vol} / \mathrm{vol})$ hexane/ethyl acetate and then with $20: 1(\mathrm{vol} / \mathrm{vol})$ hexane/ethyl acetate, and collect $10 \mathrm{ml}$ fractions.

11. Identify fractions containing 6-undecyl 4-phenylbutyrate by TLC (silica gel plates) using 9:1 (vol/vol) hexane/ethyl acetate $\left(R_{\mathrm{f}}=0.6\right)$.

12. Evaporate solvents from the pooled fractions containing 6-undecyl 4-phenylbutyrate using a rotary evaporator at ambient temperature under an aspirator vacuum ( $\sim 20$ Torr) and dry the product using a vacuum pump ( $\sim 1$ Torr).

DAUSE POINT The desired product (6-undecyl 4-phenylbutyrate) can be stored under nitrogen at ambient temperature for more than a month. ? TROUBLESHOOTING

TIMING

Steps 1 and 2, 1 h; Step 3, $24 \mathrm{~h}$ (for analogous condensation reactions with different starting acids/alcohols, 1-72 h); Step 4, 30 min; Steps 5 and 6, 1 h; Step 7, 30 min; Steps 8-10, 2 h; Steps 11 and 12, 1 h

\section{ANTICIPATED RESULTS}

Typical isolated yields of esters will be 70-95\% (largely depending on the substrates and conditions used).

Analytical data

6-Undecyl 4-phenylbutyrate. Typical isolated yields, $85-90 \% .{ }^{1} \mathrm{H} \mathrm{NMR}\left(500 \mathrm{MHz}, \mathrm{CDCl}_{3}\right) \delta 7.31-7.24(\mathrm{~m}, 2 \mathrm{H}), 7.22-7.10(\mathrm{~m}, 3 \mathrm{H}), 4.89$ (quint, $J=6.5 \mathrm{~Hz}, 1 \mathrm{H}), 2.65(\mathrm{t}, J=7.5 \mathrm{~Hz}, 2 \mathrm{H}), 2.31(\mathrm{t}, \mathrm{J}=7.5 \mathrm{~Hz}, 2 \mathrm{H}), 1.95$ (quint, $J=7.5 \mathrm{~Hz}, 2 \mathrm{H}), 1.56-1.42(\mathrm{~m}, 4 \mathrm{H}), 1.35-1.10(\mathrm{~m}, 12 \mathrm{H}), 0.87$ $(\mathrm{t}, \mathrm{J}=7.0 \mathrm{~Hz}, 6 \mathrm{H}) ;{ }^{13} \mathrm{CNMR}\left(125 \mathrm{MHz}, \mathrm{CDCl}_{3}\right) \delta 173.3,141.5,128.5,128.3,125.9,74.3,35.2,34.1,34.0,31.7,26.7,25.0,22.5,14.0 ; \mathrm{IR}$ (neat, $\left.\mathrm{cm}^{-1}\right) 1,732,1,496,1,456,1,378,1,200,1,131$; HRMS (FAB) $(\mathrm{m} / z)\left[\mathrm{M}+\mathrm{H}^{+}\right]$calculated for $\mathrm{C}_{21} \mathrm{H}_{35} \mathrm{O}_{2} 319.2637$, found 319.2635 .

18| Elute the column under pressure, initially with hexane, then with 100:1 (vol/vol) hexane/ethyl acetate, and collect $200 \mathrm{ml}$ fractions.

19| Identify fractions containing $N$-(2,6-diisopropylphenyl)- $N$-(2,4,6-mesityl)amine by thin-layer chromatography (silica gel plates) using 10:1 ( $\mathrm{vol} / \mathrm{vol})$ hexane/ethyl acetate $\left(R_{\mathrm{f}}=0.5\right)$. 
20| Evaporate solvents from the pooled fractions containing $N$-(2,6-diisopropylphenyl)- $N$-(2,4,6-mesityl)amine using a rotary evaporator at ambient temperature under an aspirator vacuum ( 20 Torr), and dry the colorless solid using a vacuum pump ( $\sim 1$ Torr) for $\sim 0.5-1 \mathrm{~h}$. The colorless solid can be stored under nitrogen at ambient temperature for more than 6 months.

\section{? TROUBLESHOOTING}

\section{Synthesis of pentafluorobenzenesulfonic acid $\bigcirc$ TIMING $\sim 1.5$ days}

21| Place $3.0 \mathrm{ml}(20 \mathrm{mmol})$ pentafluorobenzenesulfonyl chloride in a $200 \mathrm{ml}$ round-bottomed flask containing a Teflon-coated magnetic stir bar.

22| Add $50 \mathrm{ml}$ distilled water. Turn the magnetic stirrer on.

23| Fit the flask with a reflux condenser and have tap water flow through the reflux condenser.

24 Heat the flask in an oil bath $\left(80^{\circ} \mathrm{C}\right)$.

PAUSE POINT Stir the mixture vigorously at this temperature overnight $(\sim 12 \mathrm{~h})$.

I CAUTION The reaction should be conducted in a well-ventilated hood, as hydrogen chloride vapors, which are toxic and corrosive, are evolved.

25| Remove the flask from the oil bath and allow the reaction mixture to cool to ambient temperature.

26| Transfer the reaction mixture to a separatory funnel, and wash with three $10 \mathrm{ml}$ portions of hexane.

27| Transfer the aqueous solution to an appropriately sized round-bottomed flask and evaporate solvents using a rotary evaporator at $\sim 30^{\circ} \mathrm{C}$ under vacuum ( $\sim 5$ Torr).

28| Add toluene ( $\sim 10 \mathrm{ml})$ to the residue, which is colorless solid and/or oil, and evaporate solvents from the mixture using a rotary evaporator at $\sim 30^{\circ} \mathrm{C}$ under vacuum ( $\sim 10$ Torr).

PAUSE POINT Dry the resulting colorless solid using a vacuum pump ( $\sim 1$ Torr) overnight ( $\sim 12 \mathrm{~h}$ ). The dry solid pentafluorobenzenesulfonic acid can be stored under nitrogen in a $-20{ }^{\circ} \mathrm{C}$ freezer for more than a month.

$\triangle$ CRITICAL STEP The colorless solid must be obtained as monohydrate form. As pentafluorobenzenesulfonic acid is hygroscopic, store the compound under nitrogen in $\mathrm{a}-20^{\circ} \mathrm{C}$ freezer.

Synthesis of $N$-(2,6-diisopropylphenyl)- $N$-(2,4,6-mesityl) ammonium pentafluorobenzenesulfonate (4) $\bigcirc$ TIMING $\sim 1$ day 29| Place $131 \mathrm{mg}(0.53 \mathrm{mmol})$ pentafluorobenzenesulfonic acid in a $50 \mathrm{ml}$ round-bottomed flask containing a Teflon-coated magnetic stir bar and dissolve in $5 \mathrm{ml}$ toluene. Turn the magnetic stirrer on.

30| Add $156 \mathrm{mg}(0.53 \mathrm{mmol})$ of 2. Maintain stirring during the addition, and continue stirring for an additional hour.

31 Evaporate toluene from the mixture using a rotary evaporator at $\sim 30^{\circ} \mathrm{C}$ under vacuum ( $\sim 10$ Torr).

32| Add hexane $(\sim 3 \mathrm{ml})$ to wash the resulting white solid. Remove hexane using a Pasteur pipette.

PAUSE POINT Dry the now colorless solid under vacuum ( $\sim 1$ Torr) at ambient temperature for $\sim 12 \mathrm{~h}$.

$\triangle$ CRITICAL STEP The initially colorless solid obtained gradually turns green at room temperature during prolonged storage.

Therefore, store the compounds under argon in a $-20{ }^{\circ} \mathrm{C}$ freezer for up to a month to avoid coloration.

? TROUBLESHOOTING

\section{TIMING}

Synthesis of $\mathrm{N}$-(2,6-diisopropylphenyl)-N-(2,4,6-mesityl)amine (2): Steps 1-7, 1 h; Step 8, 24-48 h; Step 9, 30 min; Step 10, 20 min; Steps 11-15, 2 h; Steps 16-18, 2 h; Steps 19 and 20; 1 h

Synthesis of pentafluorobenzenesulfonic acid: Steps 22 and 23, 1 h; Step 24, 12 h; Step 25, 30 min; Step 26, 30 min;

Steps 27 and $28, \sim 14 \mathrm{~h}$

Synthesis of $\mathrm{N}$-(2,6-diisopropylphenyl)- $\mathrm{N}$-(2,4,6-mesityl)ammonium pentafluorobenzenesulfonate (4): Steps 29 and $30,1.5 \mathrm{~h}$;

Step 31, 30 min; Step 32, 30 min; Step 5, 12 h

\section{? TROUBLESHOOTING}

Troubleshooting advice can be found in Table 1. 
TABLE 1 | Troubleshooting table.

\begin{tabular}{|c|c|c|c|}
\hline Step & Problem & Possible reasons & Solution \\
\hline Step 20 & $\begin{array}{l}\text { Low yields of } N \text {-(2,6-diisopropyl- } \\
\text { phenyl)- } N \text {-(2,4,6-mesityl)amine } \\
\text { synthesis }\end{array}$ & $\begin{array}{l}\text { Reagents, especially the catalyst, } \\
\text { are of poor quality }\end{array}$ & Repeat the reaction with fresh reagents \\
\hline Step 32 & Ammonium catalysts turn green & $\begin{array}{l}\text { A small amount of the catalysts } \\
\text { gradually turns green at room } \\
\text { temperature during prolonged } \\
\text { storage }\end{array}$ & $\begin{array}{l}\text { The green-colored material seems to retain enough } \\
\text { catalytic activity. In our laboratory, the catalysts are } \\
\text { stored in a refrigerator or a freezer }\left(<0{ }^{\circ} \mathrm{C}\right) \text {. The } \\
\text { catalysts can be stored in a freezer for more than a } \\
\text { month without the appearance of any coloration }\end{array}$ \\
\hline Box 1 & Low yields of ester condensation & $\begin{array}{l}\text { Reagents, especially the catalyst, } \\
\text { are of poor quality }\end{array}$ & Repeat the reaction with fresh reagents \\
\hline
\end{tabular}

\section{ANTICIPATED RESULTS \\ Analytical data \\ $\mathrm{N}$-(2,6-Diisopropylphenyl)-N-(2,4,6-mesityl)amine (2)}

Typical isolated yield, $\sim 70-95 \% .{ }^{1} \mathrm{H}$ NMR $\left(300 \mathrm{MHz}, \mathrm{CDCl}_{3}\right) \delta 7.10(\mathrm{~s}, 3 \mathrm{H}), 6.76(\mathrm{~s}, 2 \mathrm{H}), 4.68(\mathrm{br} \mathrm{s}, 1 \mathrm{H}), 3.12$ (septet, J=6.9 Hz, $2 \mathrm{H}), 2.22(\mathrm{~s}, 3 \mathrm{H}), 1.95(\mathrm{~s}, 6 \mathrm{H}), 1.11(\mathrm{~d}, \mathrm{~J}=6.9 \mathrm{~Hz}, 12 \mathrm{H}) ;{ }^{13} \mathrm{C} \mathrm{NMR}\left(75 \mathrm{MHz}, \mathrm{CDCl}_{3}\right) \delta 143.3(\mathrm{~s}, 1 \mathrm{C}), 140.4(\mathrm{~s}, 1 \mathrm{C}), 139.1(\mathrm{~s}, 1 \mathrm{C}), 130.0$ $(\mathrm{s}, 2 \mathrm{C}), 129.0(\mathrm{~s}, 1 \mathrm{C}), 126.3(\mathrm{~s}, 2 \mathrm{C}), 124.2(\mathrm{~s}, 2 \mathrm{C}), 123.2(\mathrm{~s}, 2 \mathrm{C}), 27.9(\mathrm{~s}, 2 \mathrm{C}), 23.4(\mathrm{~s}, 4 \mathrm{C}), 20.4(\mathrm{~s}, 1 \mathrm{C}), 19.3(\mathrm{~s}, 2 \mathrm{C}) ; \mathrm{IR}\left(\mathrm{KBr}, \mathrm{cm}^{-1}\right)$ $1,484,1,466,1,442,1,340,1,270$. HRMS (FAB) $(\mathrm{m} / z)\left[\mathrm{M}+\mathrm{H}^{+}\right]$calculated for $\mathrm{C}_{21} \mathrm{H}_{29} \mathrm{~N}$ 295.2300, found 295.2308.

\section{$\mathrm{N}$-(2,6-Diisopropylphenyl)- $\mathrm{N}$-(2,4,6-mesityl)ammonium pentafluorobenzenesulfonate (4)}

Typical yield, >90\%. ${ }^{1} \mathrm{H} N M R\left(300 \mathrm{MHz}, \mathrm{CDCl}_{3}\right) \delta 7.36(\mathrm{t}, \mathrm{J}=7.8 \mathrm{~Hz}, 1 \mathrm{H}), 7.19(\mathrm{~d}, J=8.1 \mathrm{~Hz}, 2 \mathrm{H}), 6.73(\mathrm{~s}, 2 \mathrm{H}), 3.11$ (septet, $\mathrm{J}=6.8$ $\mathrm{Hz}, 2 \mathrm{H}), 2.20(\mathrm{~s}, 3 \mathrm{H}), 2.15(\mathrm{~s}, 6 \mathrm{H}), 1.07(\mathrm{~d}, J=6.6 \mathrm{~Hz}, 12 \mathrm{H}) ;{ }^{13} \mathrm{C} \mathrm{NMR}\left(125 \mathrm{MHz}, \mathrm{CDCl}_{3}\right) \delta 143.7(\mathrm{t}, J=7.8 \mathrm{~Hz}, 2 \mathrm{C}), 143.3(\mathrm{~s}, 1 \mathrm{C}), 142.0$ $(\mathrm{d}, J=255 \mathrm{~Hz}, 1 \mathrm{C}), 137.7(\mathrm{~s}, 1 \mathrm{C}), 137.2(\mathrm{~d}, \mathrm{~J}=252 \mathrm{~Hz}, 2 \mathrm{C}), 134.1(\mathrm{~s}, 1 \mathrm{C}), 132.3(\mathrm{~s}, 1 \mathrm{C}), 131.4(\mathrm{~s}, 2 \mathrm{C}), 130.9(\mathrm{~s}, 2 \mathrm{C}), 129.2(\mathrm{~s}, 2 \mathrm{C})$, $125.0(\mathrm{~s}, 2 \mathrm{C}), 118.7(\mathrm{~s}, 1 \mathrm{C}), 28.6(\mathrm{~s}, 2 \mathrm{C}), 23.5(\mathrm{~s}, 4 \mathrm{C}), 20.3(\mathrm{~s}, 1 \mathrm{C}), 19.1(\mathrm{~s}, 2 \mathrm{C}) ;{ }^{19} \mathrm{~F} \mathrm{NMR}\left(282 \mathrm{MHz}, \mathrm{CDCl}_{3}\right) \delta-138.3(\mathrm{dd}, J=6.2,21.2$ $\mathrm{Hz}, 2 \mathrm{~F}),-153.0(\mathrm{t}, \mathrm{J}=21.2 \mathrm{~Hz}, 1 \mathrm{~F}),-162.4(\mathrm{dt}, \mathrm{J}=6.2,21.2 \mathrm{~Hz}, 2 \mathrm{~F}) . \mathrm{IR}\left(\mathrm{KBr}, \mathrm{cm}^{-1}\right) 1,489,1,247,1,227,1,115$.

ACKNOWLEDGMENTS Financial support for this project was provided by JSPS KAKENHI (15205021 and 18750082), the 21st Century COE Program "Nature-Guided Materials Processing" of MEXT and Toray Science Foundation.

COMPETING INTERESTS STATEMENT The authors declare no competing financial interests.

Published online at http://www.natureprotocols.com

Reprints and permissions information is available online at http://npg.nature.com/ reprintsandpermissions

1. Otera, J. Esterification (WileyVCH, Weinheim, 2003).

2. Wakasugi, K., Misaki, T., Yamada, K. \& Tanabe, Y. Diphenylammonium triflate (DPAT): efficient catalyst for esterification of carboxylic acids and for transesterification of carboxylic esters with nearly equimolar amounts of alcohols. Tetrahedron Lett. 41, 5249-5252 (2000).

3. Funatomi, T., Wakasugi, K., Misaki, T. \& Tanabe, Y. Pentafluorophenylammonium triflate (PFPAT): an efficient, practical, and cost-effective catalyst for esterification, thioesterification, transesterification, and macrolactone formation. Green Chem. 8, 1022-1027 (2006).

4. Ishihara, K., Ohara, S. \& Yamamoto, H. Direct condensation of carboxylic acids with alcohols catalyzed by hafnium(IV) salts. Science 390, 1140-1142 (2000).

5. Manabe, K., Sun, X.-M. \& Kobayashi, S. Dehydration reactions in water. Surfactant-type Brønsted acid-catalyzed direct esterification of carboxylic acids with alcohols in an emulsion system. J. Am. Chem. Soc. 123, 10101-10102 (2001).
6. Xiang, J., Toyoshima, S., Orita, A. \& Otera, J. A practical and green chemical process: fluoroalkyldistannoxane-catalyzed biphasic transesterification. Angew. Chem. Int. Ed. 40, 3670-3672 (2001).

7. Ishihara, K., Nakagawa, S. \& Sakakura, A. Bulky diarylammonium arenesulfonates as selective esterification catalysts. J. Am. Chem. Soc. 127, 4168-4169 (2005).

8. Sakakura, A., Nakagawa, S. \& Ishihara, K. Bulky diarylammonium arenesulfonates as mild and extremely active dehydrative ester condensation catalysts. Tetrahedron 62, 422-433 (2006).

9. Ishihara, K., Sakakura, A. \& Hatano, M. Design of highly functional smallmolecule catalysts and related reactions based on acid-base combination chemistry. Synlett, 686-703 (2007)(account).

10. Vyskocil, S. Synthesis of $\mathrm{N}$-alkylated and $\mathrm{N}$-arylated derivatives of 2-amino-2'hydroxy-1,1'-binaphthyl (NOBIN) and 2,2'-diamino-1,1'-binaphthyl and their application in the enantioselective addition of diethylzinc to aromatic aldehydes. J. Org. Chem. 63, 7727-7737 (1998).

11. DiLabio, G.A., Litwinienko, G., Lin, S., Pratt, D.A. \& Ingold, K.U. Revised structure for the diphenylaminyl radical: the importance of theory in the assignment of electronic transitions in $\mathrm{Ph}_{2} \mathrm{X}^{\bullet}(\mathrm{X}=\mathrm{CH}, \mathrm{N})$ and $\mathrm{PhY}^{\bullet}\left(\mathrm{Y}=\mathrm{CH}_{2}, \mathrm{NH}, 0\right)$. J. Phys. Chem. A 106, 11719-11725 (2002).

12. Sakakura, A., Watanabe, H., Nakagawa, S. \& Ishihara, K. Unusual rate-acceleration in the Brønsted acid-catalyzed dehydration reactions: local hydrophobic environment in aggregated $N$-(2,6-diphenylphenyl)- $N$-mesitylammonium pentafluorobenzenesulfonates. Chem. Asian J. 2, 477-483 (2007).

13. Ishihara, K., Nakayama, M., Ohara, S. \& Yamamoto, H. Direct estercondensation from a 1:1 mixture of carboxylic acids and alcohols catalyzed by hafnium(IV) or zirconium(IV) salts. Tetrahedron 58, 8179-8188 (2002). 